\title{
Salicylate Degradation Test for Differentiation of Mycobacterium fortuitum from Other Mycobacteria
}

\author{
BY M. TSUKAMURA \\ The Obuso National Sanatorium, Obu (near Nagoya), Aichi Prefecture, \\ and Department of Bacteriology, Medical Faculty, \\ Nagoya University, Nagoya, Japan
}

(Received 16 February 1965)

\begin{abstract}
SUMMARY
Most isolates of Mycobacterium fortuitum decomposed salicylate and stained black the Sauton agar medium containing salicylate $(0.5$ or $1 \mathrm{mg} . / \mathrm{ml}$.); and all isolates capable of decomposing salicylate were identified as $\boldsymbol{M}$. fortuitum. Other species, including rapidly growing mycobacteria, did not decompose salicylate. Most but not all of the salicylatedecomposing isolates showed also PAS degradation and a positive 3-day arylsulphatase test. The salicylate-decomposing isolates utilized nitrite as sole nitrogen source and about one-half of them grew on a nitrite medium within 7 days. These reactions, salicylate degradation, PAS degradation, utilization of nitrite, and 3-day arylsulphatase activity, are shown to be useful for identifying $\boldsymbol{M}$. fortuitum. The 3-day arylsulphatase test showed some exceptional cases; therefore, a positive reaction in this test was not sufficient to identify $M$. fortuitum. Positive reactions in the above four tests seemed to mean that an isolate is certainly $M$. fortuitum.
\end{abstract}

\section{INTRODUCTION}

Lehmann (1947, 1961) stated that salicylate exhibited some bacteriostatic action against tubercle bacilli in Sauton medium. The present author (Tsukamura, 1962) examined the susceptibility to sodium salicylate of various mycobacterial strains in an egg medium and found that Mycobacterium tuberculosis and $\boldsymbol{M}$. bovis were specifically susceptible to this compound. Further examinations were made of rapidly growing mycobacteria on Sauton agar, with the expectation that the susceptibility might increase in this defined medium. During this study, it was found that some mycobacteria made black a Sauton agar containing high concentrations of salicylate. It was also found that most isolates which decomposed salicylate in this way showed a positive 3-day arylsulphatase test (Wayne, 1961; Kubica \& Rigdon, 1961) and utilized nitrite as sole nitrogen source ('Tsukamura \& Tsukamura, 1965). It was noticed that these reactions (salicylate degradation, 3-day arylsulphatase activity, nitrite as sole nitrogen source) usually appeared together in an isolate. The salicylate-decomposing mycobacteria consisted of $M$. fortuitum and of several strains of rapidly growing unclassified mycobacteria. An attempt was made to classify these unclassified mycobacteria according to the methods described by Gordon \& Smith (1955), Bergey's Manual (1957), and Gordon 
$\&$ Mihm (1959), and according to the amidase tests described by Boenicke (1962). The results showed that these mycobacteria belonged to $M$. fortuitum. Thus, the salicylate degradation may be specific for $M$. fortuitum.

\section{METHODS}

Isolates. The following isolates were used: Mycobacterium fortuitum (no. 605, 606, 607: R. E. Gordon); M. smegmatis (Denken, Kyushu, Jucho, Takeo); M. phlei (Denken, Kyushu); rapidly growing unclassified mycobacteria isolated from soil sources in this laboratory (14 uncoloured and 8 coloured isolates); rapidly growing unclassified mycobacteria isolated from human patients (named Yamamoto, Nishiwaki, Mimura); scotochromogens (Runyon's group II, Runyon, 1955: 16 isolates); nonphotochromogens (Runyon's group III: 18 isolates); $M$. kansasi (Forbes 84, Bostrum D-35, Nagai); $M$. avium (A 71, 3717, 4110, 4121, 11755, Flamingo, Kirchberg, Nagoya 59); M. balnei (в 913, в 916: Lausanne); M. ranae (L-17: Lausanne); M. platypoecilus (one isolate: A. J. Ross); M. piscium (one isolate: A. J. Ross); $\boldsymbol{M}$. marinum (one isolate: A. J. Ross); three isolates from tropical fishes (sf-2, Lt, sw: S. Sato). Most of these isolates were supplied by Dr K. Konno (Research Institute for Tuberculosis and Leprosy, Tohoku University), Professor K. Takeya (Department of Bacteriology, Kyushu University) and Professor S. Hibino (First Department of Internal Medicine, Nagoya University).

Salicylate degradation. This was observed in a modified Sauton medium agar containing sodium salicylate $(0.5$ or $1 \mathrm{mg} . / \mathrm{ml}$.). The composition of the Sauton agar was as follows: glycerol, $50 \mathrm{ml}$.; sodium glutamate, $4.0 \mathrm{~g}$.; $\mathrm{KH}_{2} \mathrm{PO}_{4}, \mathbf{0 . 5} \mathrm{g}$.; $\mathrm{MgSO}_{4} .7 \mathrm{H}_{2} \mathrm{O}, 0.5 \mathrm{~g}$.; sodium citrate, $2.0 \mathrm{~g}$; ; ferric ammonium citrate, $0.05 \mathrm{~g}$.; purified agar (Wako Pure Chemical Co., Osaka, Japan), 30 g.; distilled water, $950 \mathrm{ml}$. This was adjusted to $\mathrm{pH} \mathrm{7.0}$ and sodium salicylate was added to the medium, before sterilization, to final concentrations $0,0.5$ or $1 \mathrm{mg} . / \mathrm{ml}$. The medium was poured in $8 \mathrm{ml}$. quantities into tubes $(170 \times 17 \mathrm{~mm}$.) and sterilized by autoclaving at $115^{\circ}$ for $30 \mathrm{~min}$., sloped and cooled. The medium was then surface inoculated with one loopful of the stock cultures and incubated at $37^{\circ}$. Growth and change in colour were observed after 1 and 2 weeks of incubation.

Nitrite utilization as sole nitrogen source. This was tested on the slopes of the following medium: $\mathrm{NaNO}_{2}, 1.38 \mathrm{~g}$. (0.02 M); $\mathrm{KH}_{2} \mathrm{PO}_{4}, 0.5 \mathrm{~g}$; $\mathrm{MgSO}_{4} .7 \mathrm{H}_{2} \mathrm{O}$, 0.5 g.; sodium citrate, 2.0 g.; glycerol, $50 \mathrm{ml}$.; purified agar, 30 g.; distilled water, $950 \mathrm{ml}$; ; adjusted to $\mathrm{pH} 7 \cdot 0$ by addition of $10 \%(\mathrm{w} / \mathrm{v})$ KOH. Sodium nitrite was sterilized by Seitz-filtration and added to the medium aseptically. The slopes were surface inoculated with one loopful of the test strain. Growth was observed every week until the end of the third week and recorded by comparison with the growth on control medium without added nitrogen source.

Three-day arylsulphatase test. This was done according to the method of Wayne (1961).

$p$-Aminosalicylate (PAS) degradation. Degradation of sodium $p$-aminosalicylate (PAS) was tested according to the method described by Tsukamura (1961 $a, b)$. It was observed as a blackening of Ogawa egg medium containing PAS $1 \mathrm{mg} . / \mathrm{ml}$. Observation was made after 1 week of incubation at $37^{\circ}$. 
Amidase tests. These tests were done according to Boenicke (1962). Time of incubation was $15 \mathrm{hr}$. at $37^{\circ}$.

Utilization of organic acids as sole carbon sources. This was tested on the following medium: $\left(\mathrm{NH}_{4}\right)_{2} \mathrm{SO}_{4}, 2.64 \mathrm{~g}$; $\mathrm{KH}_{2} \mathrm{PO}_{4}, 0.5 \mathrm{~g}$.; $\mathrm{MgSO}_{4} .7 \mathrm{H}_{2} \mathrm{O}, 0.5 \mathrm{~g}$.; purified agar, $30 \mathrm{~g}$.; distilled water, $1000 \mathrm{ml}$.; adjusted to $\mathrm{pH} 7 \cdot 0$. Solutions of sodium salts, acetate, citrate, succinate, malate, pyruvate and benzoate, were sterilized separately by heating at $100^{\circ}$ for $5 \mathrm{~min}$. and added to the above medium aseptically to give final concentrations of $0.01 \mathrm{M}$. Growth was observed in comparison with control medium without added carbon source after 1 and 2 weeks of incubation at $37^{\circ}$.

Acid formation from carbohydrates. This was observed in the following medium: $\mathrm{NH}_{4} \mathrm{Cl}, 2.0$ g.; $\mathrm{KH}_{2} \mathrm{PO}_{4}, 0.5$ g.; $\mathrm{MgSO}_{4} .7 \mathrm{H}_{2} \mathrm{O}, 0.5 \mathrm{~g} . ; 0.2 \%$ (w/v) bromthymol blue solution in $0.02 \mathrm{M}-\mathrm{NaOH}, 20 \mathrm{ml}$; purified agar, $30 \mathrm{~g}$; ; distilled water, $1000 \mathrm{ml}$.; adjusted to $\mathrm{pH} 7 \cdot 0$. This medium was sterilized by autoclaving at $115^{\circ}$ for $30 \mathrm{~min}$. The carbohydrate solutions were sterilized separately by heating at $100^{\circ}$ for $5 \mathrm{~min}$. and added to medium aseptically to a final concentration of $0.5 \%(\mathrm{w} / \mathrm{v})$. The slopes of this medium were inoculated with one loopful of organisms, and acid formation examined after 1 and 2 weeks of incubation at $37^{\circ}$. The following carbohydrates were used: glucose, mannose, galactose, arabinose, xylose, rhamnose, trehalose, lactose, raffinose, inositol, mannitol, sorbitol.

Nitrate reduction. The bacteria to final concentration of $10 \mathrm{mg}$. wet weight bacteria/ml. were suspended in $5 \mathrm{ml}$. 0.067 $\mathrm{M}$-phosphate buffer $(\mathrm{pH} 7 \cdot 1)$ containing $0.1 \%(\mathrm{w} / \mathrm{v}) \mathrm{NaNO}_{3}$. The suspension was incubated at $37^{\circ}$ for $16 \mathrm{hr}$. and tested for nitrite. Nitrite was examined by addition of two drops of $2 \%(\mathrm{w} / \mathrm{v})$ $p$-dimethylaminobenzaldehyde in $10 \%(\mathrm{v} / \mathrm{v}) \mathrm{HCl}+1 \mathrm{ml} .10 \%(\mathrm{v} / \mathrm{v}) \mathrm{HCl}$. Control tubes contained heat-killed bacteria.

Salt tolerance. This was examined in glycerol broth containing $5 \%(\mathrm{w} / \mathrm{v}) \mathrm{NaCl}$. Growth was observed after incubation for 2 weeks at $37^{\circ}$.

Temperature response. Growth was observed on Ogawa egg medium and Löwenstein-Jensen medium after 1 and 2 weeks of incubation at $28^{\circ}, 37^{\circ}, 45^{\circ}, 52^{\circ}$.

\section{RESULTS}

The results of the salicylate degradation, PAS degradation, nitrite utilization and 3-day arylsulphatase test with various mycobacterial isolates are shown in Table 1. Among the already classified mycobacteria, only Mycobacterium fortuitum showed a positive reaction in two or more of these tests. Nitrite was used as nitrogen source by $\boldsymbol{M}$. fortuitum and gave growth within 1 week. Nitrite was also used as sole nitrogen source by $M$. smegmatis and $M$. phlei, but visible growth of these two was seen only after incubation for 2-3 weeks.

Among forty, classified or unclassified, rapidly growing mycobacteria, twenty isolates showed one or more positive reactions in the four distinguishing tests. Among these isolates, all of the strains of Mycobacterium smegmatis and $M$. phlei tested showed only use of nitrite as sole nitrogen source, showing visible growth after incubation for 2 or 3 weeks; the other activities were negative with these two organisms. Thus, these two species were separated from other strains. Among these latter strains, which are listed in Table 2, excepting the strain no. 315 which showed only the positive 3 -day arylsulphatase test, all strains including $\boldsymbol{M}$. fortuitum 
showed at least two positive reactions (Table 2). The amidase test (Boenicke, 1962), the utilization of organic acids as sole carbon sources, acid formation from carbohydrates, nitrate reduction, and $\mathrm{NaCl}$ tolerance were tested on these rapidly growing mycobacteria; the results are listed in Table 2. The results showed that the

Table 1. Salicylate degradation, p-aminosalicylate (PAS) degradation, nitrite utilization, and 3-day arylsulphatase activity by various mycobacteria

Salicylate degradation and PAS degradation were observed after one week of incubation at $37^{\circ}$.

\begin{tabular}{|c|c|c|c|c|c|}
\hline $\begin{array}{l}\text { Mycobacterium } \\
\text { strains }\end{array}$ & $\begin{array}{l}\text { No. of } \\
\text { strains } \\
\text { tested }\end{array}$ & $\begin{array}{c}\text { Salicylate } \\
\text { degradation }\end{array}$ & $\begin{array}{c}\text { PAS } \\
\text { degradation }\end{array}$ & $\begin{array}{c}\text { Nitrite } \\
\text { utilization* }\end{array}$ & $\begin{array}{c}\text { Three-day } \\
\text { aryl- } \\
\text { sulphatase } \\
\text { activity }\end{array}$ \\
\hline M. fortuitum & $\mathbf{3}$ & $+(2)$ & $+(2)$ & $+(3)$ & $+(3)$ \\
\hline M. smegmatis & 4 & - & - & $\pm(4)$ & - \\
\hline M. phlei & 2 & - & - & $\pm(2)$ & - \\
\hline M. marinum & 1 & - & - & $=$ & - \\
\hline M. platypoecilus & 1 & - & - & - & - \\
\hline M. ranae & 1 & - & - & - & - \\
\hline M. balnei & $\mathbf{2}$ & - & - & - & - \\
\hline M. piscium & 1 & - & - & - & - \\
\hline M. avium & 8 & - & - & - & - \\
\hline M. kansasi & 3 & - & - & - & - \\
\hline $\begin{array}{l}\text { Scotochromogen } \\
\text { (Group II) }\end{array}$ & 16 & - & - & - & - \\
\hline $\begin{array}{l}\text { Nonphotochromogen } \\
\text { (Group III) }\end{array}$ & 18 & - & - & $\pm(5)$ & - \\
\hline $\begin{array}{l}\text { Rapid grower } \\
\text { (Group IV) }\end{array}$ & $\mathbf{3}$ & $+(2)$ & $+(\mathbf{3})$ & $\begin{array}{l}+ \text { or } \\
\pm(3)\end{array}$ & $+(2)$ \\
\hline \multicolumn{6}{|l|}{$\begin{array}{l}\text { Rapid grower } \\
\text { (Soil sources) }\end{array}$} \\
\hline Uncoloured & 14 & $+(7)$ & $+(7)$ & $\begin{array}{l}+ \text { or } \\
\pm(7)\end{array}$ & $+(7)$ \\
\hline Coloured & 8 & - & - & $=$ & - \\
\hline
\end{tabular}

pattern of activity of unclassified, rapidly growing isolates from soil or human patients, excluding the strain no. 315, is similar to that found in the three reference strains of $M$. fortuitum.

\section{DISCUSSION}

Among the strains listed in Table 2, only the strain no. 315 differed markedly from others. This strain showed only a positive 3-day arylsulphatase test among the four distinguishing reactions. It showed no amidase activity, utilized only acetate among organic acids, and formed no acid from carbohydrates. It resembled Mycobacterium aquae (Boenicke, 1962) except that it was uncoloured. From this case, we learn that the positive 3-day arylsulphatase test is not always specific for $M$. fortuitum, even though it is sure this test is useful to screen $M$. fortuitum. On the contrary, the absence of this activity does not exclude the test strain from $\boldsymbol{M}$. fortuitum. For example, strains no. $\mathbf{3 3 0}$ and Mimura showed no 3-day arylsulphatase activity, but were considered to be $\boldsymbol{M}$. fortuitum from their over-all similarity in other characteristics (Table 2).

All strains listed in Table 2, including three strains already classified as Myco- 
Table 2. Physiological reactions of various strains of Mycobacterium in which one or more of the four distinguishing reactions were positive

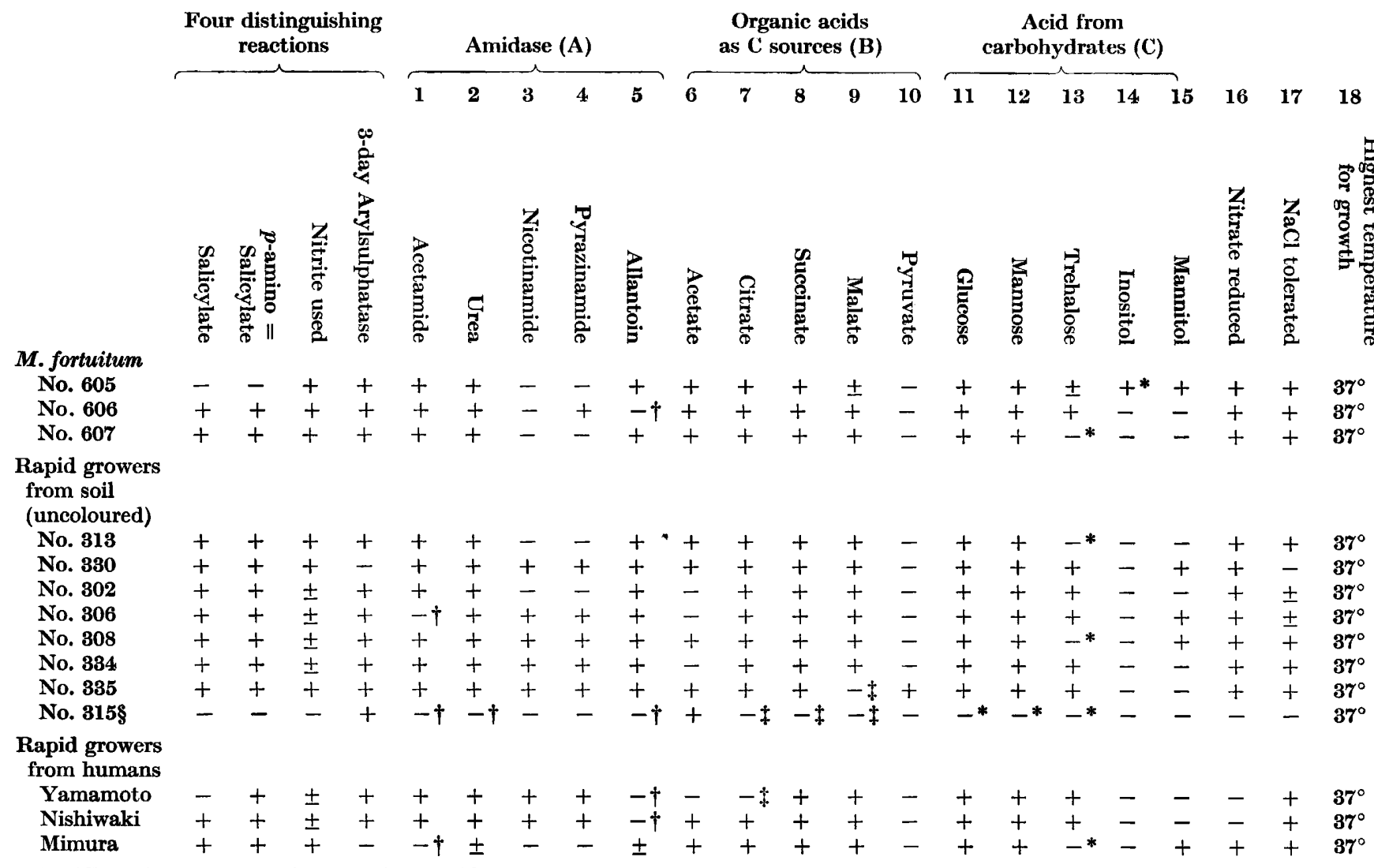

(A) All strains were negative with benzamide, isonicotinamide, salicylamide, succinamide, malonamide.

(B) All strains were negative with benzoate.

(C) All strains were negative with galactose, arabinose, xylose, rhamnose, lactose, raffinose, sorbitol.

* Deviation from the description of Bergey's Manual (1957) and Gordon \& Smith (1955) for Mycobacterium fortuitum.

$\uparrow$ Deviation from the description of $M$. fortuitum by Boenicke (1962).

\$ Deviation from the description of $M$. fortuitum by Gordon \& Smith (1955) who tested on the utilization of citrate, succinate, malate, benzoate.

$\S$ No. 315 showed pattern of $M$. aquae, except that it was uncoloured; no acid from carbohydrates.

Symbols for nitrite utilization: + , positive growth within one week; \pm , positive growth within 2 weeks; - , negative growth after 3 weeks. 
bacterium fortuitum, showed a few deviations from the typical characteristics of M. fortuitum (Gordon \& Smith, 1955; Bergey's Manual, 1957; Gordon \& Mihm, 1959), but the unclassified strains shown in Table 2, excluding strain no. 315, were thought to be $\boldsymbol{M}$. fortuitum from their similarity to the reference strains. It was noted that these strains showed two or more positive distinguishing reactions (Table 2). On the other hand, no other strains showed such reactions (Table 1). In view of these results, it was thought that the four distinguishing reactions are useful to distinguish $\boldsymbol{M}$. fortuitum from other mycobacteria.

Wayne (1961) and Kubica \& Rigdon (1961) stated that Mycobacterium fortuitum may be differentiated from other rapidly growing mycobacteria by its positive arylsulphatase test. However, as shown in this study, there are some exceptional cases (strains no. 315, 330, Mimura). Growth at 7 days with nitrite as sole nitrogen source may be specific for $M$. fortuitum (Tsukamura \& Tsukamura, 1965), but a negative reaction does not exclude $\boldsymbol{M}$. fortuitum (Table 2). Similarly, positive reactions of the salicylate degradation and the PAS degradation seem to be specific for $\boldsymbol{M}$. fortuitum; but all strains of $\boldsymbol{M}$. fortuitum do not show these reactions (Table 2). We must say that it is impossible to detect $M$. fortuitum by one characteristic, but, from the results of this study, it seems to be possible to do so by use of four marker characteristics. When a test strain shows two or more positive reactions among the four distinguishing reactions (salicylate degradation, PAS degradation, growth on nitrite medium within 7 days, 3-day arylsulphatase test), the strain may be identified as $M$. fortuitum.

Cattaneo, Morellini, Penso \& Vicari (1954) and Penso, Cattaneo, Morellini \& Vicari (1955) stated that Mycobacterium piscium and a number of isolates from cold-blooded animals darkened PAS-containing media. It was a peculiar fact that they stated that $\boldsymbol{M}$. minetti $(\boldsymbol{M}$. fortuitum) showed a negative reaction, based upon the observation on one isolate. Tsukamura $(1961 a, b)$ observed that certain mycobacteria isolated from the soil blackened PAS-containing media (at that time, the author did not know of the Italian work) and showed that the coloured formazan was due to the change of PAS catechol.

There remains some question as to whether Mycobacterium fortuitum is the only species degrading PAS, because the Italian authors stated that $M$. piscium and other mycobacteria from cold-blooded animals darkened the PAS medium. In the present study, it was observed that one strain of $M$. piscium and one strain (в 913) of $M$. balnei made a PAS medium brown after more than 2 weeks. Three strains from tropical fishes also made the medium dark after incubation for 2-3 weeks. However, it seemed easy to distinguish the reaction of $M$. fortuitum from the false reaction of other mycobacteria, since the $M$. fortuitum reaction was much stronger and appeared sooner, i.e. after 1 week incubation.

In contrast to the PAS degradation, salicylate degradation appeared to be clearly restricted to $\boldsymbol{M}$. fortuitum. Growth of the mycobacteria, which showed a false reaction in the PAS degradation, was inhibited on the Sauton agar containing sodium salicylate $\mathbf{0 . 5}$ or $1 \mathrm{mg} . / \mathrm{ml}$., and no change in colour was observed. In addition, salicylate degradation differed from the PAS degradation. This was shown by the fact that the strain Yamamoto decomposed PAS but did not decompose salicylate (Table 2). The degradation product of salicylate by $\boldsymbol{M}$. fortuitum has now been shown to be catechol (Tsukamura 1965). 
This study was supported in part by a grant from the National Sanatorium Department of the Ministry of Welfare and Health of Japan. The author wishes to express his appreciation to Professor K. Ogasawara (Department of Bacteriology, Nagoya University) for his kind advice. He expresses his appreciation to Professors S. Hibino and K. Takeya, and to Dr K. Konno for their supply of the isolates used in the present study.

\section{REFERENCES}

Bergey's Manual of Determinative Bacteriology (1957). 7th ed., Ed. by R. S. Breed, E. G. D. Murray \& N. R. Smith, p. 694. Baltimore, U.S.A.: Williams and Wilkins Co.

Boenicke, R. (1962). L'identification des mycobactéries a l'aide de méthodes biochimiques. Bull. Un. int. Tuberc. 32, 13.

Cattaneo, C., Moreluini, M., Penso, G. \& Vicari, G. (1954). Il particolare comportamento di alcuni micobatteri nei confronti dell'acido p-aminosalicilico. Riv. Tuberc. Mal. Appar. resp. 2, 498.

Gordon, R. E. \& Minm, J. M. (1959). A comparison of four species of mycobacteria. J. gen. Microbiol. $21,736$.

Gondon, R. E. \& SMITH, M. M. (1955). Rapidly growing, acid fast bacteria. II. Species' description of Mycobacterium fortuitum Cruz. J. Bact. 69, 502.

Kubica, G. P. \& Rigdon, A. L. (1961). The arylsulfatase activity of acid-fast bacilli. III. Preliminary investigation of rapidly growing acid-fast bacilli. Am. Rev. resp. Dis. 83, 737 .

Lehmann, J. (1947). Recherches sur le bacille tuberculeux. Action bactériostatique, différentiation in-vitro. Revue gén. Sci. pur. appl. 54, 222.

Lehmann, J. (1961). Chemische und experimentelle Grundlagen der PAS-Therapie. Wien. med. Wschr. 111, 803.

Penso, G., Cattaneo, C., Morellini, M. \& Vicari, G. (1955). Studi e ricerche sui micobatteri. XIV. Sul metabolismo del PAS in alcune specie di micobatteri insensibili al PAS. Ric. Ist. sup. Sanità, $18,17$.

Runyon, E. H. (1955). Veterans Administration-National Tuberculosis Association Cooperative Study of Mycobacteria. Am. Rev. Tuberc. 72, 866.

Tsukamura, M. (1961 $a)$. Certain saprophytic mycobacteria from soil sources forming a red color product from PAS. Am. Rev. resp. Dis. 84, 916 (Letter to the editors).

Tsuramura, M. (1961 b). Formation of a red color product from PAS by certain mycobacteria. Jap. J. Tuberc. 9, 70.

Tsuramura, M. (1962). Differentiation of Mycobacterium tuberculosis from other mycobacteria by sodium salicylate susceptibility. Am. Rev. resp. Dis. 86, 81 .

Tsuramura, M. (1965). Conversion of salicylate to catechol by Mycobacterium fortuitum. J. gen. Microbiol. 41, 317.

Tsukamura, M. \& Tsukamura, J. (1965). Differentiation of mycobacteria by utilization of nitrite as sole nitrogen source. J. Bact. 89, 1442.

WAYNE, L. G. (1961). Recognition of Mycobacterium fortuitum by means of a three-day phenolphthalein sulfatase test. Am. J. clin. Path. 36, 185. 